\title{
ON THE LEGAL PROCEDURE AND EXERCISING THE RIGHTS OF THE INDIVIDUAL
}

\author{
Igor V. Rostovshchikov \\ Volgograd State University, Volgograd, Russian Federation
}

\begin{abstract}
Introduction: the issues of legal procedure (course of law) have been and remain ones of the most relevant in the legal theory and practice. The article draws attention to the legal procedures in terms of their evolution in the legal life of society, as well as their role as an important condition for the operation and effectiveness of the legal regulations. The purpose of the article is to show the importance of the legal procedure for the enjoyment of the rights and freedoms of the individual. The methodological framework for the work is the general scientific dialectical method of cognition, as well as the analytical, historical and legal, comparative law, formal legal methods, etc. Results: the problems of the legal procedures can be considered in various socio-legal and functional aspects. The constant attention to the legal procedures of the scientists and practitioners is justified, especially in the context of the forms of implementation of the legal norms, which often has a procedural nature established by the law. Conclusions: The procedural and legal provisions are an integral part of the mechanism of the legal regulation and the mechanism of the enjoyment of many rights of the individual.

Key words: legal procedure, legal regulation, application of law, enjoyment of the rights and freedoms of the individual.

Citation. Rostovshikov I.V. On the Legal Procedure and Exercising the Rights of the Individual. Legal Concept, 2018, vol. 17, no. 4, pp. 64-70. DOI: https://doi.org/10.15688/lc.jvolsu.2018.4.9

УДК $347: 342.716$

Дата получения статьи: 15.09 .2018

ББК 67.404 .06

Дата принятия статьи: 22.10.2018
\end{abstract}

\section{О ЮРИДИЧЕСКОЙ ПРОЦЕДУРЕ И РЕАЛИЗАЦИИ ПРАВ ЛИЧНОСТИ}

\author{
Игорь Викторович Ростовщиков \\ Волгоградский государственный университет, г. Волгоград, Российская Федерация
}

Введение: вопросы правовой (юридической) процедуры были и остаются одними из весьма актуальных в юридической теории и практике. В статье обращено внимание на юридические процедуры с точки зрения их эволюции в правовой жизни общества, а также их роли как важного условия действия и результативности правовых установлений. Цель статьи состоит в том, чтобы показать значимость юридической процедуры для реализации прав и свобод личности. Методологическую основу работы составляет общенаучный диалектический метод познания, а также аналитический, историко-правовой, сравнительно-правовой, формально-юридический методы и др. Результаты: проблемы юридических процедур можно рассматривать в различных социально-правовых и функциональных аспектах. Постоянное внимание к юридическим процедурам ученых и практиков вполне оправдано, особенно в контексте форм реализации правовых норм, которые часто имеют установленный законом процедурный характер. Выводы: процедурно-правовые установления есть неотъемлемая составляющая механизма правового регулирования и механизма реализации многих прав личности.

Ключевые слова: юридическая процедура, правовое регулирование, применение права, реализация прав и свобод личности.

Цитирование. Ростовщиков И. В. О юридической процедуре и реализации прав личности // Legal Concept = Правовая парадигма. - 2018. - Т. 17, № 4. - C. 64-70. - DOI: https://doi.org/10.15688/lc.jvolsu.2018.4.9 


\section{Введение}

Понятие «процедура» имеет древнее происхождение, и складывалось в качестве своеобразного регулятора поведения людей при реализации различных общественных норм. Именно в процедурах, опосредующих получение субъектами необходимых им благ, а также упорядочивающих поведение субъектов в социально значимых целях, наглядно проявляется их сущность и специфическая ценность. Соответственно необходимость осмысления правовой природы и значения юридической процедуры предопределена объективными причинами, в частности ее ролью в реализации человеком своих прав и свобод. С учетом признания высшей ценности прав и свобод человека процедуры их реализации обретают большое значение, существенно влияя на конечный результат реализации.

\section{Юридическая процедура как социальное и правовое явление}

Процедурные механизмы в той или иной степени характерны для нормативного упорядочивания различных общественных отношений [1, с. 379]. В этом смысле определенный процедурный порядок может иметь место при осуществлении даже некоторых этических норм, религиозных обрядов и т. п. Между тем процедура преимущественно присуща осуществлению тех социальных норм, которые отличаются признаками формальной определенности, четкой документальной фиксации, государственной властности, то есть прежде всего юридических норм. Не случайно процедуры рождаются там, где возникает потребность нормативно установить не только возможное и должное поведение лиц, но и сам порядок поведения. Иными словами, многие нормы материального права в своем осуществлении требуют определенных процессуальных процедур, которые гарантируют особый порядок их воплощения и защиты.

По мере становления в тех или иных государствах прав личности появлялись и процедуры их реализации. Многовековую историю имеет специальная юридическая процедура реализации права личности на неприкосновенность - «хабеас корпус». Это традиционное наименование судебного приказа, который направляется должностному лицу, ответственному за содержание арестованного под стражей. Приказ предписывает доставить задержанного или арестованного по его требованию в суд для проверки судом законности задержания или ареста. Впервые эта процедура была введена в Англии Законом 1679 г. Habeas Corpus Act. Если суд принимает решение о необоснованности задержания, ареста или заключения, лицо, подвергшееся этим санкциям, должно быть немедленно освобождено. Лицо, выпущенное на свободу в порядке производства на основе «хабеас корпус», не может быть вторично задержано, арестовано или подвергнуто заключению по тем же основаниям.

Будучи одним из базовых институтов уголовного процесса англосаксонской системы судопроизводства и важнейшей формой судебной защиты прав личности, процедура «хабеас корпус» была органически воспринята правом США и многих других стран, продолжая действовать.

Разумеется, при становлении и развитии законодательства о юридических процедурах в зарубежных странах и России процедуры не отличались совершенством, не всегда выделялись их виды. Проблема эта была связана с тем, что на тот период в российской и зарубежной теории не были разработаны концептуальные подходы к понятию процедуры, ее роли в механизме правового регулирования [7; 10; 11].

\section{Начало осмысления в отечественной правовой науке роли юридической процедуры в реализации прав личности}

В отечественной научной литературе теория юридической процедуры стала активно разрабатываться еще в советский период. Общий подход к юридической процедуре состоял в видении ее как нормативно установленного порядка осуществления юридической деятельности, обеспечивающего реализацию норм материального права и основанных на них материальных правоотношений, охраняемого от нарушения правовыми санкциями. В качестве свойств процедуры выделялись, прежде всего: а) доступность; б) оперативность; в) надежность; г) одинаковость; д) бе- 


\section{ТЕОРИЯ И ПРАКТИКА ГОСУДАРСТВЕННО-ПРАВОВОГО РАЗВИТИЯ}

зопасность. Способность права обеспечивать эти свойства, удовлетворять потребность личности в них как раз и образует, на взгляд автора, его ценность [9, с. 102-103].

Ведущая цель юридической процедуры состоит в обеспечении реализации основной, то есть материальной правовой нормы, основанного на ней основного правоотношения. В этом состоит природа юридической процедуры и ее функциональный смыл. Юридическая процедура выступает в качестве процессуальная формы, которая определяет стадии юридического процесса, их цели, последовательность. Она конкретизирует действия на каждой стадии, основание совершения и взаимосвязь этих действий, а также способы их оформления и фиксации.

Еще в советской юридической литературе юридическую процедуру начинали рассматривать применительно к реализации прав личности. Здесь особо можно выделить коллективную монографию («Юридическая процессуальная форма: теория и практика», Москва, 1976 г.). Научная работа представляла собой попытку объединить усилия ученых ряда отраслей юридической науки в исследовании процессуальной формы в советском праве. В ней новаторски ставился комплекс вопросов теории и практики правотворческой и правоприменительной деятельности, давалась расширенная характеристика определенных элементов процессуальной формы в сфере реализации норм государственного права, административного права и др. Наконец, в монографии было целенаправленно обращено внимание на роль юридической процедуры для прав и свобод личности, сферы их реализации и охраны. Посредством закрепленных в законе процессуально-процедурных форм устанавливается, по выражению одного из авторов монографии Н.В. Витрука, известная «алгоритмичность» порядка правореализующей деятельности, процедура и последовательность правореализующих действий, их содержание и направленность на наиболее полное и точное достижение цели в использовании субъективного права, исполнения материально-правовой позитивной обязанности [3, с. 107].

Отмечалось, что отсутствие юридической регламентации процедурных порядков ре- ализации прав человека подчас затрудняет их осуществление либо делает невозможным их реализацию. Подчеркивалось, что если установленная законом процедура совершенна и действует эффективно, то надо ожидать от ее действия положительных результатов. И, напротив, если установленный законом порядок не срабатывает, то соответствующие права и свободы не воплощаются в жизнь. Было обращено внимание, что различные виды прав и свобод личности отличаются и процедурой реализации в зависимости от специфики и своеобразия этих прав [3, с. 200].

В последующем в постсоветской юридической науке развивались сформулированные фундаментальные положения о юридической процедуре в контексте реализации прав личности. Разумеется, это делалось с учетом признания прав человека неотъемлемыми, высшей ценностью согласно Конституции РФ (ст. 2).

\section{Значение юридической процедуры в реализации прав и свобод личности}

Теоретические разработки в области юридической процедуры закономерно позволили экстраполировать их результаты на вопросы практического воплощения прав и свобод человека, увидеть многоплановую роль процедуры в механизме их реализации [4]. Как известно, каждое право или свобода личности имеют свой характер и при необходимости порядок реализации. Реализация некоторых организуется самой личностью, по ее инициативе, вне прямой зависимости от кого бы то ни было. Так осуществляются многие гражданские права и свободы: свободы совести и вероисповедания, свободы мысли и слова, права определения и указания своей национальной принадлежности и др. И если закон предоставляет возможность самому обладателю права (свободы) в полном объеме определять порядок его использования, то можно говорить об «инициативной», «произвольной» форме использования. В итоге человек сознательно, добровольно и свободно проявляет свою волю в определенных нормами закона границах, независимо от кого-либо воплощает свою волю посредством реализации своего правомочия [6]. Единственное требование к таким действиям человека - они не долж- 
ны затрагивать права и свободы других лиц (ч. 3 ст. 17 Конституции РФ).

Наряду с вышеуказанной инициативной формой использования прав и свобод личности существует процессуально-процедурная, когда закон с той или иной степенью определенности предусматривает регламент их использования. Процессуально-процедурный порядок представляет собой собственно юридическую конструкцию реализации прав (это менее касается субъективных свобод в силу специфики их содержания). Он обычно предполагает согласованность активных действий правообладателя и обязанных лиц, четкую нормативную фиксированность этих действий по форме, методам, средствам, времени, месту осуществления и т. д.

Согласованность действий определена прежде всего через систему юридических фактов, юридических (фактических) составов, которые вызывают указанные действия, а также сами ими порождаются. Одновременно могут регламентироваться и организационные мероприятия (уведомить лицо о решении, выдать документ и др.). К примеру, трудовое правоотношение возникает на основании юридического состава, в который, помимо достижения гражданином установленного законом возраста, получения им профессиональной подготовки, наличия вакансии и др., обычно входят: его официальное письменное волеизъявление, заключение трудового соглашения, приказ руководителя о назначении на должность. Характерно указание в Гражданском кодексе РФ [13] на форму совершения ряда сделок в рамках реализации гражданином права собственности, когда требуется нотариальное удостоверение сделки (ст. 163) или ее государственная регистрация (ст. 164), что, в свою очередь, является обязанностью нотариуса или учреждения юстиции. Некоторые нормативные акты непосредственно нацелены на подробную регламентацию процедур осуществления прав и свобод человека и гражданина, как, например, Федеральный закон «О порядке выезда из Российской Федерации и въезда в Российскую Федерацию» [2].

Указание в праве на процедурный порядок реализации прав человека крайне важно, когда пользование правом зависит от действий не только самого носителя права, но и других субъектов, когда необходимо их взаимодействие в рамках конкретных правоотношений.

Процедурно-правовой порядок реализации, в свою очередь, можно подразделить на два вида. Данная классификация зависит от наличия или отсутствия правоприменительной деятельности органов государственной власти и местного самоуправления. Там, где нет такой правоприменительной деятельности, речь идет о простом процедурно-правовом порядке реализации прав человека, при котором закон с той или иной степенью определенности предусматривает способ реализации человеком своих прав. В этом случае закон обычно устанавливает последовательность действий самого обладателя права, а также содержание этих действий. Какие поступки будет совершать человек, осуществляя свое право - это его усмотрение. Главное, чтобы это было в рамках закона. Если есть возможность выбора процедур, то человек может остановиться на той процедуре, которая соответствует его интересам. Так, например, согласно ст. 21 Федерального закона «Об основах охраны здоровья граждан в Российской Федерации» [14] реализуется право гражданина на обращение в различные медицинские организации и к различным врачам.

Другой вид процедурно-правового порядка реализации прав личности включает правоприменительную деятельность соответствующих органов и должностных лиц. Дело в том, что немалое количество прав человека, хотя и имеются все фактические обстоятельства для их претворения в жизнь, не может быть использовано человеком и реализовано им без вынесения властными субъектами необходимых актов правоприменения. В данном случае процедура реализации прав человека предусмотрена в нормативно-правовом порядке как обязательная к соблюдению.

Цель правоприменения - не решение охранительных задач, а удовлетворение практических потребностей в надлежащем функционировании отдельных общественных отношений, предоставление гражданину пути к благам, лежащим в основе тех или иных прав, но не произвольного пути, а с «посредничеством» государства.

Каков перечень прав личности, реализация которых требует применения права ком- 


\section{ТЕОРИЯ И ПРАКТИКА ГОСУДАРСТВЕННО-ПРАВОВОГО РАЗВИТИЯ}

петентным субъектом? Не создает ли подобная зависимость получения и использования личностью законного блага от посторонних субъектов неудобств и дополнительных сложностей (как юридического, так и организационного порядка). Ведь общеизвестно, что правоприменение подчас способно быть своеобразной помехой реализации прав личности. Примером тому может служить обычная практика тоталитарных стран, где установлены разрешительные порядки реализации права выбора гражданами места жительства, выезда за границу, создания общественных и религиозных объединений, выпуска печатных изданий, проведения митингов, собраний и т. д.

С другой стороны, даже объективно обусловленные правоприменительные действия в процессе реализации прав личности увеличивают протяженность процесса. Появляются дополнительные субъекты - участники процесса реализации, возникают текущие правоотношения, появляются проблемы психологического свойства.

В процессе реализации прав личности требуемое применение юридических норм осуществляется чаще всего по ее инициативе. Обладающее властными полномочиями лицо должно отреагировать на исковые действия человека в установленном порядке. Понятно, обращение человека изначально не предопределяет характера выносимого решения (разрешить, зарегистрировать, отменить запрет и др.). Однако субъект правоприменения процессуально связан с волеизъявлением личности, что обязывает его надлежаще решить вопрос по существу обращения или же мотивировать отказ. А это, в свою очередь, позволяет гражданину в установленном порядке обжаловать неудовлетворяющее его решение. Хотя здесь есть некоторая дискуссионность относительно подмены дозволения в рамках права человека на его притязания, чтобы использовать дозволение [8, с. 50]. Между тем, как отмечается в юридической литературе, в любом случае, правовые механизмы должны конструироваться таким образом, чтобы они действовали как оптимальные способы достижения определенности в действиях субъектов права [5, с. 144].
В некоторых ситуациях возникновение, изменение или прекращение правоотношений между индивидом, использующим свое право, и государственным органом происходит по инициативе последнего. Выносимый при этом правоприменительный акт выступает как неотъемлемый юридический «этап» процедуры реализации права личности либо его защиты в случае каких-либо посягательств на него, воздействия иных негативных факторов. Например, при использовании избирательного права необходимо включение гражданина в списки избирателей (регистрация), что осуществляется местными органами и, как правило, не требует специального волеизъявления гражданина. Подобным образом решается вопрос о заслуженном поощрении работника, присвоении очередных воинских (специальных) званий и др.

Реально демократическое государство в принципе не заинтересовано в искусственном усложнении использования гражданами своих прав. В первую очередь это права, в основе которых лежат значительные блага материально-имущественного плана. Пользование такими правами связано с распределением социальных фондов потребления (ресурсов) между правообладателями (право на жилище, собственности на землю, на труд и вознаграждение за него, на пенсию и иное социальное обеспечение и т. д.).

Как правило, не остается без внимания государства и реализация прав, опосредующих хотя и не материальные, но весьма существенные для человека социальные блага и индивидуальные ценности и одновременно не безразличные для общества в целом (право на вступление в брак, на получение высшего образования, на интеллектуальную собственность, на медицинскую, особенно стационарную помощь и т. д.). Так, создавая особый регистрационный порядок заключения брака, государство имеет цель выявить добровольное согласие будущих супругов, удостовериться в достижении ими брачного возраста, исключить возможность многоженства, пресечь иные злоупотребления правом и тем самым обеспечить желающим вступить в брак юридическую основу для создания полноценной семьи, в чем, собственно, заинтересовано любое цивилизованное государство. 
Правоприменительная деятельность компетентных субъектов имеет большое значение при реализации и таких прав личности, когда затрагиваются интересы не только ее одной, но и многих других людей, подчас всего общества, когда возникает потребность сочетания и взаимной согласованности этих интересов, когда безответственное поведение индивида может повлечь неблагоприятные последствия. Так, вынесение соответствующих решений является непременным условием для осуществления избирательных прав, права на получение гражданства, на объединение и др. Задачами поддержания правопорядка, личной и общественной безопасности обусловлено требование соблюдения специальных юридических процедур вывоза из страны антикварных произведений искусства, приобретения оружия, получения права на управление транспортным средством и др.

В процессе правомерно ориентированной реализации прав и свобод личности выносятся следующие акты: регламентирующие; регистрационные; разрешительные; удостоверяющие (акты о признании); констатирующие (оценивающие); предписывающие (директивные); запрещающие; аннулирующие (отменяющие). Об актах правоприменения в механизме реализации прав личности подробнее см., например: [12, с. 95-109]. Автор полагает возможным выделить еще и такой вид актов, как акты об отказе в заявлении гражданина в интересах законности и безопасности гражданина.

\section{Выводы}

Юридические процедуры часто выступают составной частью общего процесса реализации прав человека. Они зависят от объективных условий: от уровня социально-экономического развития страны; развитости демократии; состояния правопорядка; международных договоров; уровня культуры, нравственности, традиций общества и т. д. Вместе с тем процедуры реализации не должны противоречить существу тех или иных прав и свобод человека; препятствовать их полноценной реализации, присущей правовому демократическому государству.

\section{СПИСОК ЛИТЕРАТУРЫ}

1. Антология мировой правовой мысли. В 5 т. T. 1. Античный мир и Средневековье: V-XVII вв. М. : Мысль, 1999. - 750 с.

2. Ведомости Съезда народных депутатов Российской Федерации и Верховного Совета Российской Федерации. - 1993. - № 32. - Ст. 1227.

3. Витрук, Н. В. Процессуальные формы реализации и охраны прав и обязанностей граждан / Н. В. Витрук // Юридическая процессуальная форма: теория и практика. - М., 1976. - 280 с.

4. Громова, Н. В. Административная юстиция (история и современность) : дис. ... канд. юрид. наук / Громова Наталья Васильевна. - М., 2002. - 170 с.

5. Кашанский, Р. С. Конкретизация как способ совершенствования правотворчества / Р. С. Кашанский // Правовая политика и правовая жизнь. 2018. - № 1. - С. 140-145.

6. Копейчиков, В. В. Стадии реализации прав и свобод личности / В. В. Копейчиков // Реализация прав граждан в условиях развитого социализма. М., 1983. -264 c.

7. Новая история стран Европы и Америки. Первый период : учебник / под ред. В. Н. Виноградова, И. М. Гусева. - М. : Высш. шк., 1997. $415 \mathrm{c}$.

8. Попов, В. В. Проблемы системной связи субъективных прав и юридических обязанностей / В. В. Попов // Правовая парадигма. - 2017. - Т. 16, № 3. - C. 47-51. - DOI: https://doi.org/10.15688/ lc.jvolsu.2017.3.8.

9. Рабинович, П. М. Социалистическое право как ценность / П. М. Рабинович. - Львов : Вища шк., 1985. - $168 \mathrm{c}$.

10. Романов, А. К. Правовая система Англии : учеб. пособие / А. К. Романов. - М. : Дело, 2002. -344 с.

11. Российское законодательство X-XX вв. В 9 т. Т. 2. Законодательство периода образования и укрепления Русского централизованного государства. - М. : Юрид. лит., 1985. - 520 с.

12. Ростовщиков, И. В. Юридические процедуры и реализация прав человека / И. В. Ростовщиков, А. Г. Тарасова. - Волгоград : Изд-во ВолгГМУ, 2014. -252 c.

13. Собрание законодательства Российской Федерации. - 1994. - № 32. - Ст. 3301.

14. Собрание законодательства Российской Федерации. - 2011. - № 48. - Ст. 6724.

\section{REFERENCES}

1. Antologiya mirovoy pravovoy mysli. $V 5 t$. T. 1. Antichnyy mir i Srednevekovye: $V-X V I I v v$ [Anthology of World Legal Thought. In 5 vols. Vol. 1. 


\section{ТЕОРИЯ И ПРАКТИКА ГОСУДАРСТВЕННО-ПРАВОВОГО РАЗВИТИЯ}

Ancient World and the Middle Ages: the $5^{\text {th }}-17^{\text {th }}$ Centuries]. Moscow, Mysl Publ., 1999. 750 p.

2. Vedomosti Syezda narodnykh deputatov Rossiyskoy Federatsii $i$ Verkhovnogo Soveta Rossiyskoy Federatsii, 1993, no. 32, art. 1227.

3. Vitruk N.V. Protsessualnye formy realizatsii $i$ okhrany prav $i$ obyazannostey grazhdan. Yuridicheskaya protsessualnaya forma [Procedural Forms of Realization and Protection of the Rights and Duties of Citizens]. Moscow, 1976. 280 p.

4. Gromova N.V. Administrativnaya yustitsiya (istoriya i sovremennost): dis. ... kand. yurid. nauk [Administrative Justice (the Past and the Present). Cand. jurid. sci. diss.]. Moscow 2002. 170 p.

5. Kashanskiy R.S. Konkretizatsiya kak sposob sovershenstvovaniya pravotvorchestva [Specification as a Way to Improve Law-Making]. Pravovaya politika i pravovaya zhizn, 2018, no. 1, pp. 140-145.

6. Kopeychikov V.V. Stadii realizatsii prav $i$ svobod lichnosti. Realizatsiya prav grazhdan $v$ usloviyakh razvitogo sotsializma [Stages of Implementation of the Rights and Freedoms of People. Implementation of the Rights of Citizens in the Conditions of Developed Socialism]. Moscow, 1983. 264 p.

7. Vinogradov V.N., Gusev I.M. Novaya istoriya stran Evropy i Ameriki. Pervyy period [New History of the Countries of Europe and America. First Period]. Moscow, Vysshaya shkola Publ., 1997. 415 p.
8. Popov V.V. Problemy sistemnoy svyazi subyektivnykh prav i yuridicheskikh obyazannostey [Problems of Systemic Communication of Subjective Rights and Legal Duties]. Pravovaya paradigma [Legal Concept], 2017, vol. 16, no. 3, pp. 47-51. DOI: https://doi.org/10.15688/lc.jvolsu.2017.3.8.

9. Rabinovich P.M. Sotsialisticheskoe pravo kak tsennost [Socialist Law as a Value]. Lvov, Vysshaya shkola Publ., 1985. 168 p.

10. Romanov A.K. Pravovaya sistema Anglii [The Legal System of England]. Moscow, Delo Publ., 2002.344 p.

11. Rossiyskoe zakonodatelstvo $X-X X v v$. $V 9 t$. T. 2. Zakonodatelstvo perioda obrazovaniya $i$ ukrepleniya Russkogo tsentralizovannogo gosudarstva [Russian Legislation of the $10^{\text {th }}-20^{\text {th }}$ Centuries. In 9 vols. Vol. 2. Legislation of the Period of Formation and Strengthening of the Russian Centralized State]. Moscow, Yurid. lit. Publ., 1985. 520 p.

12. Rostovshchikov I.V., Tarasova A.G. Yuridicheskie protsedury $i$ realizatsiya prav cheloveka [Legal Procedures and the Realization of Human Rights]. Volgograd, Izd-vo VolgGMU, 2014. 252 p.

13. Sobranie zakonodatelstva Rossiyskoy Federatsii [Collected Legislation of the Russian Federation], 1994, no. 32, art. 3301.

14. Sobranie zakonodatelstva Rossiyskoy Federatsii [Collected Legislation of the Russian Federation], 2011, no. 48, art. 6724.

\section{Information about the Author}

Igor V. Rostovshchikov, Doctor of Sciences (Jurisprudence), Professor, Head of Department of Theory and History of Law and State, Volgograd State University, Prosp. Universitetsky, 100, 400062 Volgograd, Russian Federation, rostbox@list.ru, https://orcid.org/0000-0002-0271-6470

\section{Информация об авторе}

Игорь Викторович Ростовщиков, доктор юридических наук, профессор, заведующий кафедрой теории и истории права и государства, Волгоградский государственный университет, просп. Университетский, 100, 400062 г. Волгоград, Российская Федерация, rostbox@list.ru,https://orcid.org/0000-0002-0271-6470 